\title{
Prevalence of low back pain among the working Ethiopian population: A systematic review and meta-analysis
}

\author{
Amanuel Godana Arero ${ }^{1, *}$, Godana Arero ${ }^{2}$, Shimels Hussien Mohammed ${ }^{3}$, Sahar Eftekhari ${ }^{4}$ \\ ${ }^{1}$ Students' Scientific Research Center, Tehran University of Medical Sciences, Tehran, Iran. \\ ${ }^{2}$ Department of Public Health, Adama Hospital Medical College, Adama, Ethiopia. \\ ${ }^{3}$ Department of Community Nutrition, School of Nutritional Sciences and Dietetics, Tehran \\ University of Medical Sciences, Tehran, Iran. \\ ${ }^{4}$ School of Medicine, International Campus, Tehran University of Medical Sciences, Tehran, Iran. \\ *. Corresponding author: Amanuel Godana Arero, Students' Scientific Research Center, Tehran University of \\ Medical Sciences, Tehran, Iran. Tel: +989377845753, E-mail: amanuel.godana@yahoo.com.
}

Cite this article: Arero, A.G.; Arero, G.; Mohammed, S.H.; Eftekhari, S. Prevalence of low back pain among working Ethiopian population: A systematic review and meta-analysis. Int J Epidemiol Health Sci 2021;2(1): e06. Doi: 10.51757/IJEHS.2.1.2021.47841.

\begin{abstract}
Background and objective: Low back pain (LBP), as a musculoskeletal disorder, remains a common health problem and is one of the most prevalent occupational injuries affecting adults living in both developed and developing countries. To increase the power and improve the prevalence estimates of LBP among the working Ethiopian population, a comprehensive meta-analysis was carried out.

Methods: A comprehensive systematic literature search was conducted through multiple international electronic bibliographic databases such as Web of Science, Pub Med, EMBASE, Scopus, and Google Scholar. Population-based studies with the prevalence of LBP among the working population living in Ethiopia were included. Meta-analyses, meta-regression, and sensitivity analysis was conducted. Funnel plot symmetry visualization followed by Begg's rank correlation, and Egger's regression asymmetry test methods were performed to detect the existence of publication bias. Heterogeneity between studies was assessed by using the Cochrane $\mathrm{Q}$ and $\mathrm{I}^{2}$ statistics.

Results: Overall, 719 articles were identified and 13 articles with 6513 participants met the inclusion criteria for metaanalyses. The pooled point and twelve-month prevalence of LBP among the working Ethiopian population was $49 \%$ (95\% CI: 40-58) and 56\% (95\% CI: 49-62), respectively.

Conclusion: The results showed a high prevalence of LBP among the working Ethiopian population, especially among teachers. We believe that prevention strategies addressing the early onset of LBP among the working population would most likely be the answer to the burden of LBP on future economies in Ethiopia.
\end{abstract}

Keywords: Low back pain, Epidemiology, Occupational injury, Working population, Ethiopia

\section{Abbreviations:}

LBP: Low back pain

GBD: Global Burden of Disease

DALYs: Disability adjusted life years

YLDs: Years lived with disability

HIV/AIDS: Human Immunodeficiency Virus/Acquired Immune Deficiency Syndrome

CI: Confidence interval 


\section{Introduction}

It is believed that lower back pain (LBP) is one of the most prevalent musculoskeletal conditions affecting adults living in both developed and developing countries (1-4). LBP is defined as the pain or discomfort in the lumbar region of the spine between the lower costal margins and the inferior gluteal folds with or without leg pain (i.e., sciatica) (1-4). LBP remains one of the most common health problems affecting $50-80 \%$ of adults among the working age population who may experience in their lifetime and its prevalence or incidence has been found to be raised by increasing age $(3,4)$. It is estimated that $46 \%$ of workers in European countries (5) and about $20 \%$ of workers in USA $(6,7)$ reported LBP. Besides, LBP is the major cause of work absence and activity restriction worldwide, imposing a high economic burden on individuals, families, communities, industries, and governments $(8,9)$. Direct costs for LBP in USA were estimated between \$20 billion and $\$ 98$ billion, with indirect annual costs included the total cost estimates are as high as $\$ 200$ billion $(10,11)$. According to the Global Burden of Disease (GBD) 2010 study, the overall burden of LBP arising from workplace exposure was estimated about 21.8 million (95\% Confidence interval (CI): 14.5-30.5) disabilityadjusted life years (DALYs) and is currently, the sixthhighest burden and is the cause of more years lived with disability (YLDs) globally than any other condition (12-14). Even though, the literature on the prevalence of LBP is accumulating; however, the most part of studies are restricted and only available for developed countries, which comprise less than $20 \%$ of the world's population. Having more information for the prevalence of LBP in the working population in developing countries such as Ethiopia, may assist in the understanding of the global LBP burden and its management. Thus, the purpose of this review aims to systematically appraise published Disease prevalence studies conducted in Ethiopia and estimate LBP prevalence in the working population, to ascertain whether LBP is of concern in Ethiopia, as it is globally.

\section{Methods}

This systematic review and meta-analysis was conducted based on the recommendations of MOOSE (Meta-analysis of Observational Studies in Epidemiology) guideline (15), and PRISMA (Preferred Reporting Items for Systematic Reviews and Meta-Analysis) guideline (16). The work was registered in PROSPERO (protocol registration number: CRD42020188523). The comprehensive search for published epidemiological research in the musculoskeletal disorders in general, regardless of etiology, and LBP specifically conducted in Ethiopia with no restriction of period and yielded 719 hits. As the main objective of our current review focused solely on the prevalence of LBP, studies that reported musculoskeletal disorders other than LBP and LBPrelated to underlying diseases (e.g., Rheumatology, Cancer, etc.) were excluded. Studies that are not specifically conducted to report LBP but reported LBP prevalence were included. After removing duplicates and screening of titles and articles, 43 studies were selected for full-text review. Consequently, 13 eligible studies were included in this review (18-30). The literature search, selection, and reviewing process are depicted in the PRISMA flow diagram Figure 1.

\section{Characteristics of studies}

All studies conducted in the field of the prevalence of LBP in Ethiopia, regardless of the publication period, were reviewed and included in this study. Studies could report the prevalence of musculoskeletal disorders by providing subgroup data for the prevalence of LBP. Subjects included in the studies could be from any race, gender, and age. All Studies included were published in English.

\section{Data sources}

A systematic literature search was conducted in multiple international electronic bibliographic databases such as Web of Science, PubMed, EMBASE, Scopus, and Google Scholar until May 2020. The main keywords used for this search were: low back pain, musculoskeletal pain, occupational injury, prevalence, and Ethiopia. The First Reviewer (AGA) searched independently, and the second reviewer (GA) checked the finding.

\section{Study selection}

Inclusion criteria dealt with the cross-sectional studies that present the prevalence of LBP among Ethiopian working population and conducted in Ethiopia. Exclusion criteria included irrelevant studies, articles without adequate data regarding observations, studies that linked LBP with other diseases, duplicate studies and dissertations, conference proceedings, commentaries/letters, and other grey literature were excluded from this review. 


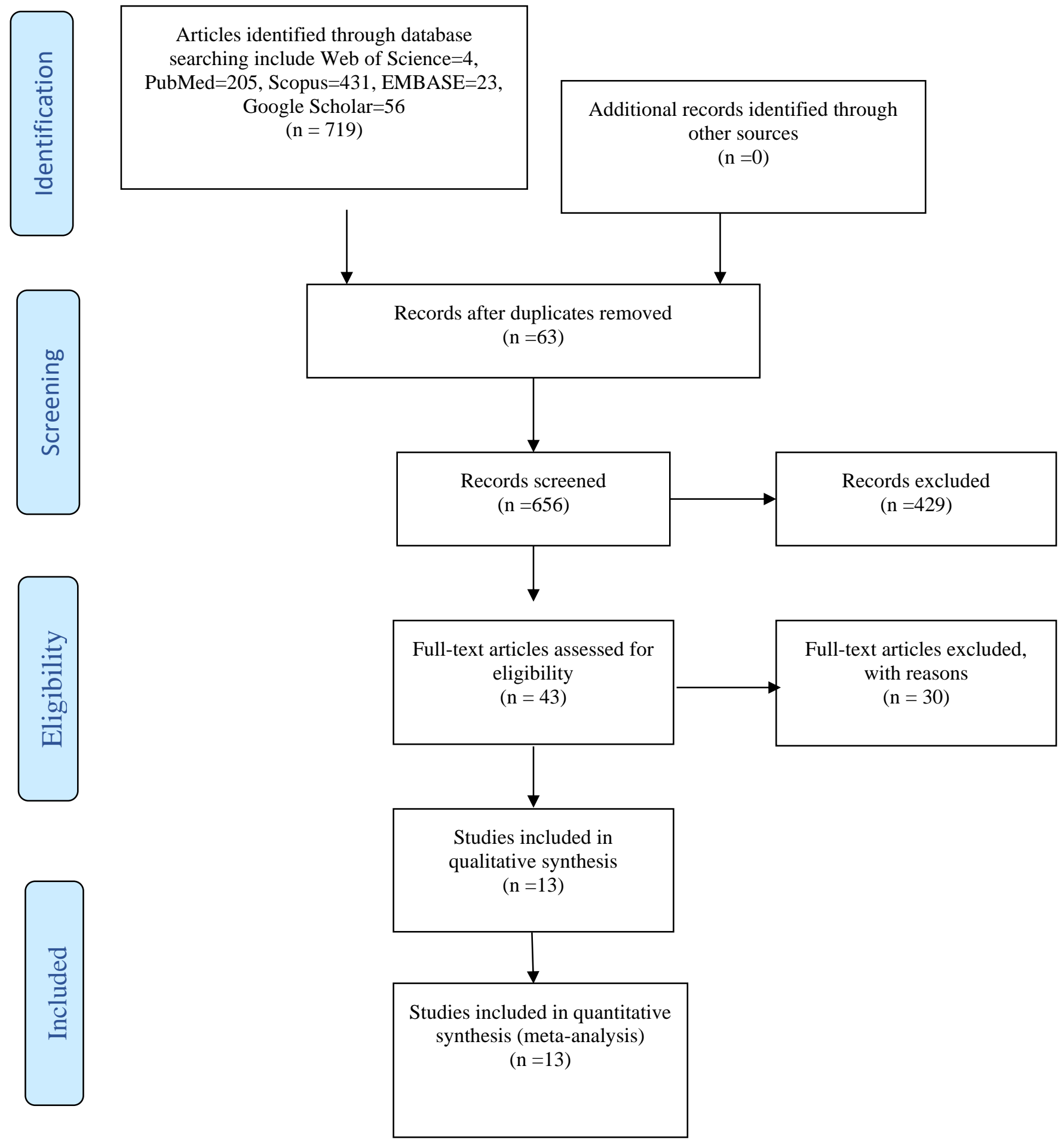

Figure 1. Flow chart of study selection 
Arero, A.G. et al.

Table 1. Study characteristics

\begin{tabular}{|c|c|c|c|c|c|c|c|c|}
\hline Author & City/region & Study design & Setting & Tool & Population & $\begin{array}{l}\text { Sample } \\
\text { size }\end{array}$ & Age & Gender \\
\hline Lette at el.(2018) & Jimma & Cross sectional & Community & Q & $\begin{array}{l}\text { Construction } \\
\text { workers }\end{array}$ & 360 & $14-45+$ & $\mathrm{F} / \mathrm{M}$ \\
\hline Kebed at el.(2019) & Mekelle & Cross sectional & School & Q & Teachers & 656 & $30-40+$ & $\mathrm{F} / \mathrm{M}$ \\
\hline Beyen at el.(2013) & Gonder & Cross sectional & School & $\mathrm{Q}$ & Teachers & 662 & $30-40+$ & F/M \\
\hline Abebaw at el.(2018) & Addis Ababa & Cross sectional & Community & Q & Teachers & 827 & $<30-59+$ & $\mathrm{F} / \mathrm{M}$ \\
\hline Wanamo at el.(2017) & Addis Ababa & Cross sectional & Community & Q & Taxi drivers & 422 & NM & $\mathrm{F} / \mathrm{M}$ \\
\hline TeferaZele at el.(2020) & $\begin{array}{l}\text { Central \& } \\
\text { southern Ethiopia }\end{array}$ & Cross sectional & Community & Q & $\begin{array}{l}\text { Traditional } \\
\text { weaving } \\
\text { workers }\end{array}$ & 824 & NM & $\mathrm{F} / \mathrm{M}$ \\
\hline Regassa at el.(2018) & Jimma & Cross sectional & Hospital & $\mathrm{Q}$ & Nurses & 333 & $20-40+$ & $\mathrm{F} / \mathrm{M}$ \\
\hline Wami at el.(2019) & Gonder & Cross sectional & Community & Q & $\begin{array}{l}\text { Low wage } \\
\text { workers }\end{array}$ & 422 & $<24-29+$ & $\mathrm{F} / \mathrm{M}$ \\
\hline
\end{tabular}

$\mathrm{Q}=$ Questionnaire, $\mathrm{NM}=$ Not mentioned, $\mathrm{F}=$ Female, $\mathrm{M}=$ Male, AHMC=Adama Hospital Medical College

Table 2. Methodological appraisal of included studies $(n=13)$

\begin{tabular}{|l|l|l|l|l|l|l|l|l|l|l|l|l|l|l|}
\hline Author & $\mathbf{1}$ & $\mathbf{2}$ & $\mathbf{3}$ & $\mathbf{4}$ & $\mathbf{5}$ & $\mathbf{6}$ & $\mathbf{7}$ & $\mathbf{8}$ & $\mathbf{9}$ & $\mathbf{1 0}$ & $\begin{array}{l}\text { Sum } \\
\text { score }\end{array}$ & Score (\%) & MA \\
\hline Lette at el.(2018) & + & - & + & + & + & + & + & + & - & + & $8 / 10$ & 80 & + \\
\hline Belay at el.(2016) & + & - & + & + & + & + & + & + & + & + & $9 / 10$ & 90 & + \\
\hline Kebed at el.(2019) & + & - & + & + & + & + & + & + & + & + & $8 / 10$ & 80 & + \\
\hline Beyen at el.(2013) & + & - & + & + & + & + & + & + & - & + & $8 / 10$ & 80 & + \\
\hline Yosef at el.(2019) & + & - & + & + & + & + & + & + & + & + & $9 / 10$ & 90 & + \\
\hline Abebaw at el.(2018) & + & - & + & + & + & + & + & + & + & - & $8 / 10$ & 80 & + \\
\hline Wanamo at el.(2017) & + & - & + & + & + & + & + & + & + & + & $9 / 10$ & 90 & + \\
\hline TeferaZele at el.(2020) & + & - & + & + & + & + & + & + & - & + & $8 / 10$ & 80 & + \\
\hline Abebe at el.(2015) & + & - & + & + & + & + & + & + & - & + & $8 / 10$ & 80 & + \\
\hline Gebreyesus, at el.(2019) & + & - & + & + & + & + & + & + & + & + & $9 / 10$ & 90 & + \\
\hline Mekonnen (2019) & + & - & + & + & + & + & + & + & + & + & $9 / 10$ & 90 & + \\
\hline Regassa at el.(2018) & + & - & + & + & + & + & + & + & - & + & $8 / 10$ & 80 & + \\
\hline Wami at el.(2019) & + & - & + & + & + & + & + & + & - & + & $8 / 10$ & 80 & + \\
\hline
\end{tabular}

$+=$ Criteria fulfilled; $-=$ Criteria not fulfilled; MA= Methodologically acceptable 


\section{Data extraction and study quality assessment}

Data extraction and quality assessment were done by two independent reviewers (AGA and GA). Discrepancy was resolved by discussion between two reviewers. For all included articles, a predesigned form was used for data extraction sheet in Excel software, including author names, city/region, study design, year of publication, study setting, data collection period, population, age, gender, working experience, body mass index, type of standard questionnaire, sample size, responsive rate, the prevalence of LBP, and the study quality score. The methodological quality critical appraisal tool used in a systematic and meta-analysis into the prevalence of LBP in Africa (17) was adapted to this review. A cut-off of $80 \%$ was considered. The average methodological score of all studies was $83 \%$.

\section{Analytical approach}

From the extracted data, the pooled point and twelve-month prevalence of LBP among working Ethiopian population, with $95 \% \mathrm{CI}$, were calculated for conducting meta-analysis. Heterogeneity between studies was assessed using the Cochrane Q and $\mathrm{I}^{2}$-statistics, which quantifies the proportion of variance explained by between-study heterogeneity. According to Higgins and colleagues (26), heterogeneity was measured by $\mathrm{I}^{2}$ and divided into four categories, $\mathrm{I}^{2}<25 \%, 25-49 \%, 50-75 \%$, and $>75 \%$ which represent no, low, moderate, and high levels of heterogeneity, respectively. Sensitivity analysis was performed using a random-effect model. Funnel plot symmetry visualization followed by Begg's rank correlation and Egger's regression asymmetry test methods were performed to detect the existence of publication bias. The point and twelve-month prevalence estimate of each study with a 95\% CI were used to estimate the pooled prevalence. Furthermore, to assess the possible sources of variation, univariate meta-regression was also conducted. Data analysis was done using STATA software version 15.0. A significance level of 0.05 was considered for the P-value.

\section{Results}

\section{General description of the reviewed studies}

Descriptive data extracted from the 13 included studies were reported as an overview summary (Table 1). The studies were published from 2013-
2020. The sample size of the studies ranged from 300 to 824 individuals. Altogether, the 13 studies included 6513 individuals, of whom $60 \%$ were males and $40 \%$ females. All studies reported a response rate from $90.4-100 \%$. The mean response rates were $95.38 \%$. Except for two studies $(29,30)$ which included only male subjects, the rest of studies included both genders. The recall periods for LBP were reported as point and twelve-month prevalence. LBP prevalence was usually reported as the point or period prevalence. Point prevalence was measured at a single point in time (i.e., the number of people reporting LBP on the day of a survey) and period prevalence was measured over a specified period, usually six months or 1 year (i.e., those people who reported to have LBP in the past six-months or twelve-months) (31).

\section{Methodological appraisal}

The methodological quality scores of the included studies are reported in Table 2. All studies were descriptive with a quality score of higher than $80 \%$. Ratings for each study were compared between the two evaluators, AGA and GA, with solving the disagreements by discussion.

\section{Prevalence of LBP}

Three studies reported the point prevalence of LBP (18, $20,21)$. The point prevalence of LBP was estimated about 49\% (95\% CI: 40-58). Heterogeneity between the point prevalence of LBP was assessed and there was high heterogeneity $\left(\mathrm{chi}^{2}=30.5\right.$, d.f. $\left.=2, \mathrm{p}=0.001, \mathrm{I}^{2}=93.44 \%\right)$. The summary analysis for point prevalence of LBP is shown in Figure 2. Twelve studies reported the twelvemonth prevalence of LBP (19-30). The twelve-month prevalence of LBP was estimated about 56\% (95\% CI: 4962). Heterogeneity between the twelve-month prevalence of LBP was assessed and there was high heterogeneity $\left(\mathrm{chi}^{2}=298.06\right.$, d.f. $\left.=11, \mathrm{p}=0.001, \mathrm{I}^{2}=96.3 \%\right)$. The summary analysis for the twelve-month prevalence of LBP is shown in Figure 3. 


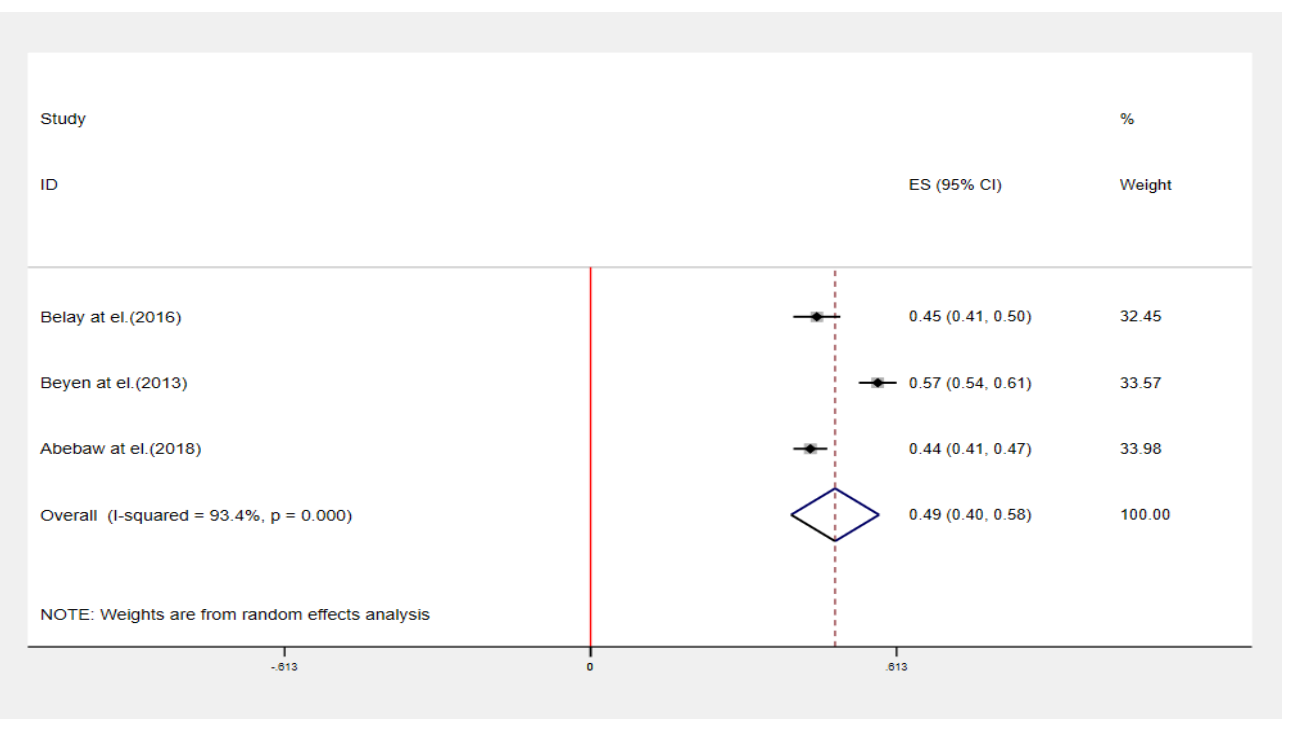

Figure 2. Pooled point prevalence of LBP (Random effects model used) ES: Effect Size, CI: Confidence Interval

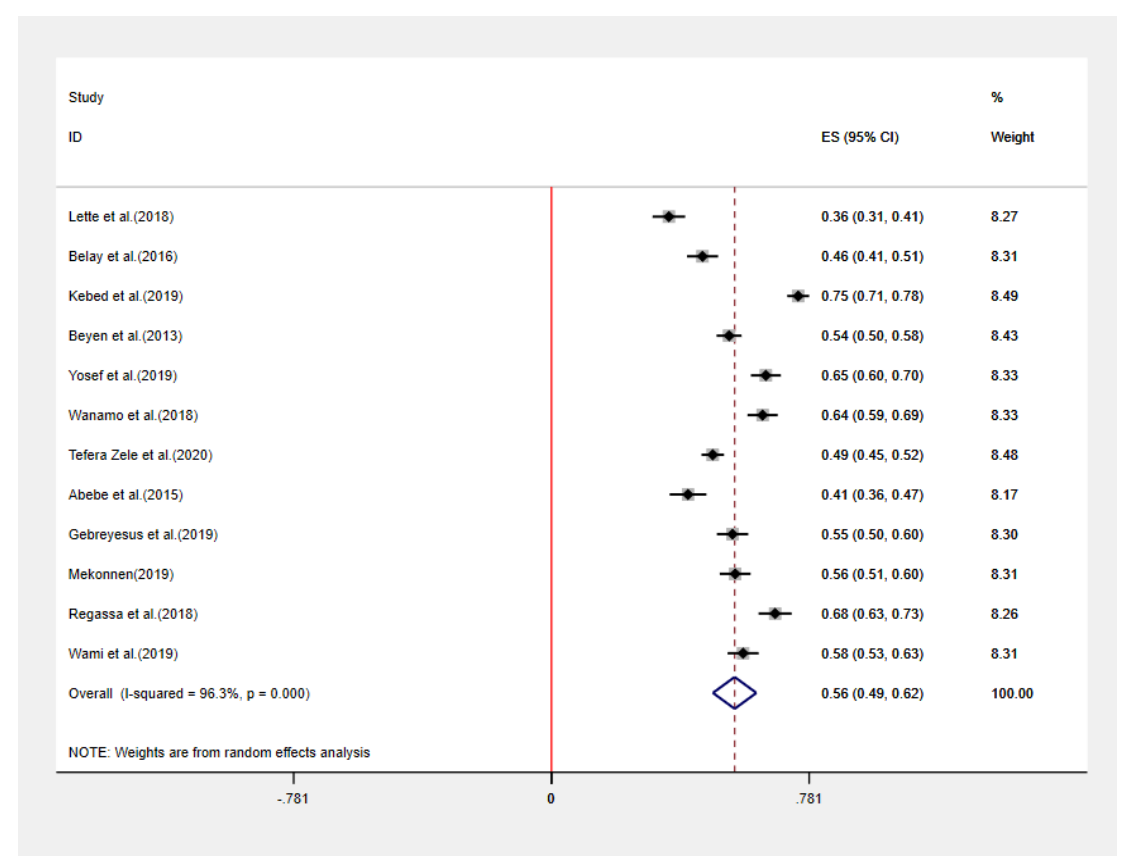

Figure 3. Pooled twelve-month prevalence of LBP (Random effects model used) ES- effect sizes, CI- Confidence interval 
Table 3. A summary of socioeconomic and behavioral factors associated with low back pain among working Ethiopian population

\begin{tabular}{|c|c|c|}
\hline Population & Reference & Main Associated factors of low back pain \\
\hline Construction workers & 24 & Absence of vocational training, khat chewing, and working overtime \\
\hline Nurses & 20 & $\begin{array}{l}\text { Working shift, physical activities at work, sleep disturbance and felt little pleasure by } \\
\text { doing things }\end{array}$ \\
\hline Teachers & 23 & sleeping disturbance, prolonged standing, and irregular physical exercise \\
\hline Teachers & 21 & $\begin{array}{l}\text { Doing regular physical exercise, provisions of office at working institution and } \\
\text { satisfaction with working environment and culture }\end{array}$ \\
\hline Truck drivers & 30 & $\begin{array}{l}\text { Smoking cigarette, physical inactivity, chronic diseases other than LBP, frequent lifting or } \\
\text { carrying heavy objects, and perceived improper sitting posture while driving, perceived } \\
\text { job }\end{array}$ \\
\hline Teachers & 18 & $\begin{array}{l}\text { Ergonomics training, enough teachers in school, prolonged sitting posture and poor work } \\
\text { place social environment }\end{array}$ \\
\hline Taxi drivers & 29 & $\begin{array}{l}\text { Driving over ten years, uncomfortable seat, Frequency of lifting loads, Previous job that } \\
\text { involved prolonged sitting, lack of physical exercise }\end{array}$ \\
\hline Traditional weaving workers & 27 & $\begin{array}{l}\text { Working seat without backrest, working } 7 \text { days in , workplace thermal level as warm, } \\
\text { work at night and awareness on workplace safety as a protective effect }\end{array}$ \\
\hline AHMC staffs & 19 & $\begin{array}{l}\text { Obesity, stressed often, those worked in seated position more than six hours and those } \\
\text { with long year experience }\end{array}$ \\
\hline Teachers & 22 & Being female sex, smoking habit, doing regular physical and sleep disturbance \\
\hline Barbers & 25 & Age, alcohol use, lack of safety training, working posture, and length of employment \\
\hline Nurses & 26 & $\begin{array}{l}\text { Lifting and transferring dependent patients, giving wound care, working in medical ward } \\
\text { and Intensive care unit, working in mal-positions, working in the same positions for long } \\
\text { period of time working with disoriented patients and bending or twisting back during } \\
\text { work }\end{array}$ \\
\hline Low wage workers & 28 & $\begin{array}{l}\text { Being temporary employee, type of job which requires reaching/overstretching, engaging } \\
\text { in a job that requires repetitive bending, making }>30 \text { beds per day }\end{array}$ \\
\hline
\end{tabular}

\section{$\mathrm{AHMC}=$ Adama Hospital Medical College}

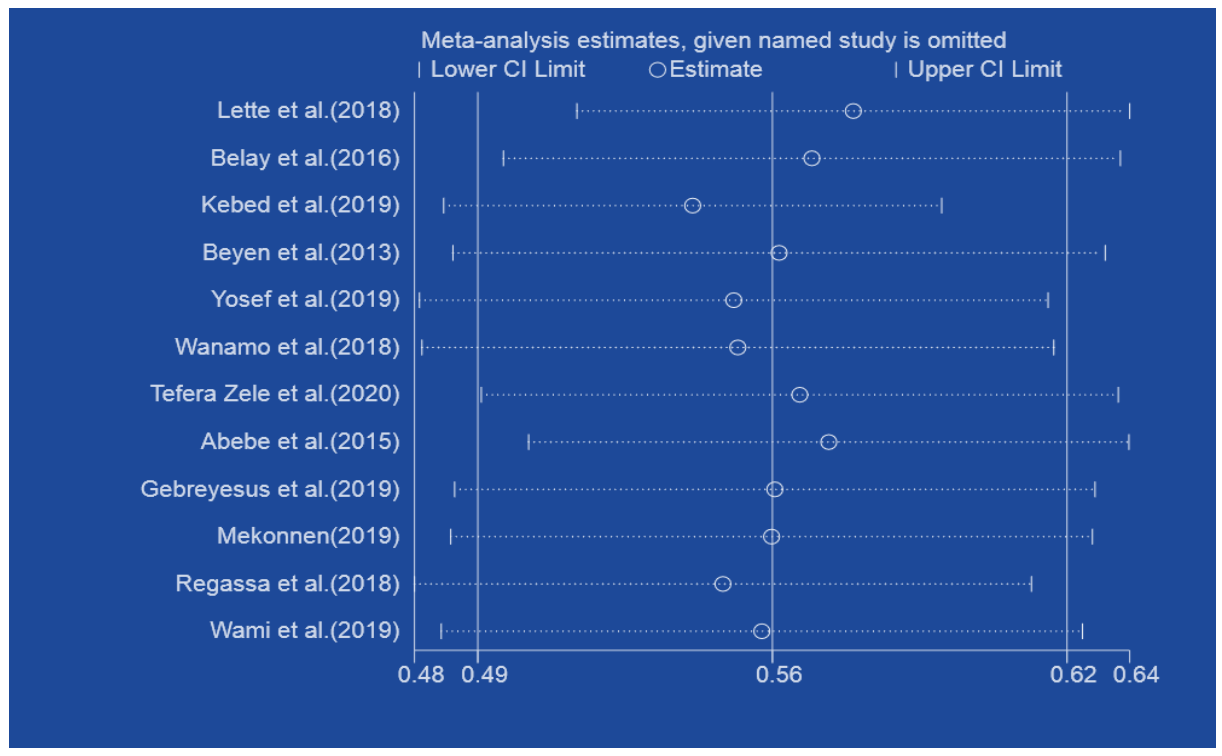

Figure 4. Sensitivity analysis of included studies to determine Prevalence of low back pain among working Ethiopian population. 


\section{Socioeconomic and behavioral factors associated with low back pain}

All studies (18-30) provided sufficient data to determine associations with potential risk factors. The main association factors were directly extracted from these publications and summarized in Table 3.

\section{Sensitivity analysis}

Sensitivity analysis of LBP among the working Ethiopian population was performed using a randomeffect model. Sensitivity analysis was carried out by excluding each study step-by-step from the metaanalysis and comparing point prevalence estimate before and after removing a single study. Accordingly, removing a single study did not alter the pooled prevalence estimate considerably, with sensitivity analysis ranging from $53.75 \%$ (when reference (23) was removed) and $57.34 \%$ (when reference (24) was removed). Figure 4 shows these results.

\section{Meta-regression}

Meta-regression analysis showed that there was no significant statistical relationship between the year of publication and the prevalence of the LBP $(\mathrm{P}$-value $=$ 0.345) (Figure 5).

\section{Publication bias}

The funnel plot symmetry visual inspection was used to assess the presence of publication bias qualitatively. This identified that the publication bias was not significant (Figure 6). Besides, the absence of publication bias was statistically confirmed by Egger's weighted regression test $(\beta=-11.87,(95 \% \mathrm{CI}:-32.5$ to $-8.76 \% ; \mathrm{p}=0.229)$ and Begg's rank test $(\mathrm{P}=0.244)$. Therefore, we did not adjust the final pooled prevalence estimate.

\section{Discussion}

Meta-analyses of the observational data collected from the eligible studies provided a summary estimates of the point and twelve-month prevalence. Among those studies that reported point prevalence, LBP prevalence ranged from $44-58 \%$. And among those provided twelve-month prevalence, LBP prevalence ranged from $36-75 \%$.

Extracted data showed that teachers reported the highest rates in both point and twelve-month prevalence $(21,23)$, possibly due to the prolonged standing during sessions in addition to other potential risk factors. Point prevalence and twelve-month prevalence of LBP in the working Ethiopian population was found to be higher than recently reported estimates of the global LBP prevalence in the general population $(12,33,34)$. A systematic review that included general population studies and published in 2012, reported the global prevalence of LBP obtained from 165 studies from 54 countries around the globe, and published between 1980 and 2009 (33). In our review, the point prevalence of LBP was estimated about 49\% (95\%CI: 40-58), which is considerably higher than the global LBP prevalence estimate (18.3\%) reported by Hoy and colleagues (33), and the prevalence of LBP among Africans estimate (39\%) reported by Morris and colleagues (17). Furthermore, twelve-month prevalence of LBP was estimated about 56\% (95\%CI: 49-62), which is substantially higher than the global LBP prevalence estimate (38.5\%) reported by Hoy and colleagues (33), but relatively equal to the prevalence of LBP among Africans estimate $(57 \%)$ reported by Morris and colleagues (17).

The summary estimates from our current review were compared to northern American and western European countries. It was found that the point prevalence of LBP was considerably higher than estimates provided for Canada (28.7\%), Denmark (12-13.7\%), and Sweden $(23.2 \%)$, and was comparable to Germany (39.2\%) and Belgium (33\%) (34). Furthermore, twelve-month prevalence of LBP was considerably higher than Spain (20\%), and similar to Denmark (56\%) and Ukraine (50.3\%) (34). The pooled prevalence LBP for both point and twelve-month prevalence were compared to particularly LBP prevalence among the working population reported in developed countries such as the USA (25.7\%), Canada (28\%) and United Kingdom (18\%) (35), and showed that our estimate is much higher than these countries. The findings of our review, therefore, reiterate the fact that LBP is a burden and is therefore a major public health concern among developing countries $(12,36,37)$. Despite the high burden, LBP lacks enough attention compared to the infectious diseases and epidemics such as HIV/AIDS in developing countries (38). The successful development and implementation of strategies and policies to address the burden of LBP among the working population in Ethiopia or countries with emerging economies is therefore necessary $(17,39)$. 


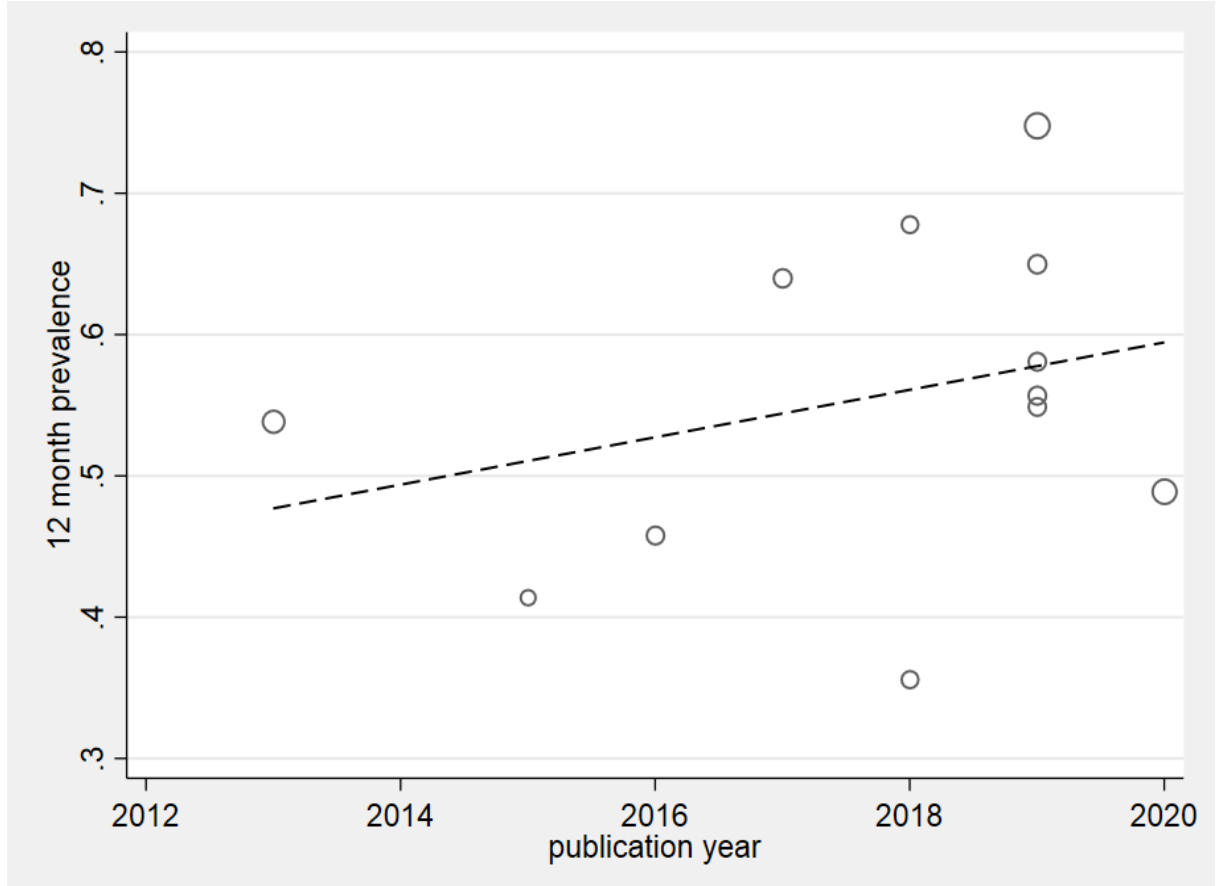

Figure 5. Meta-regression plot of Prevalence of low back pain among working Ethiopian population based on year of publication.

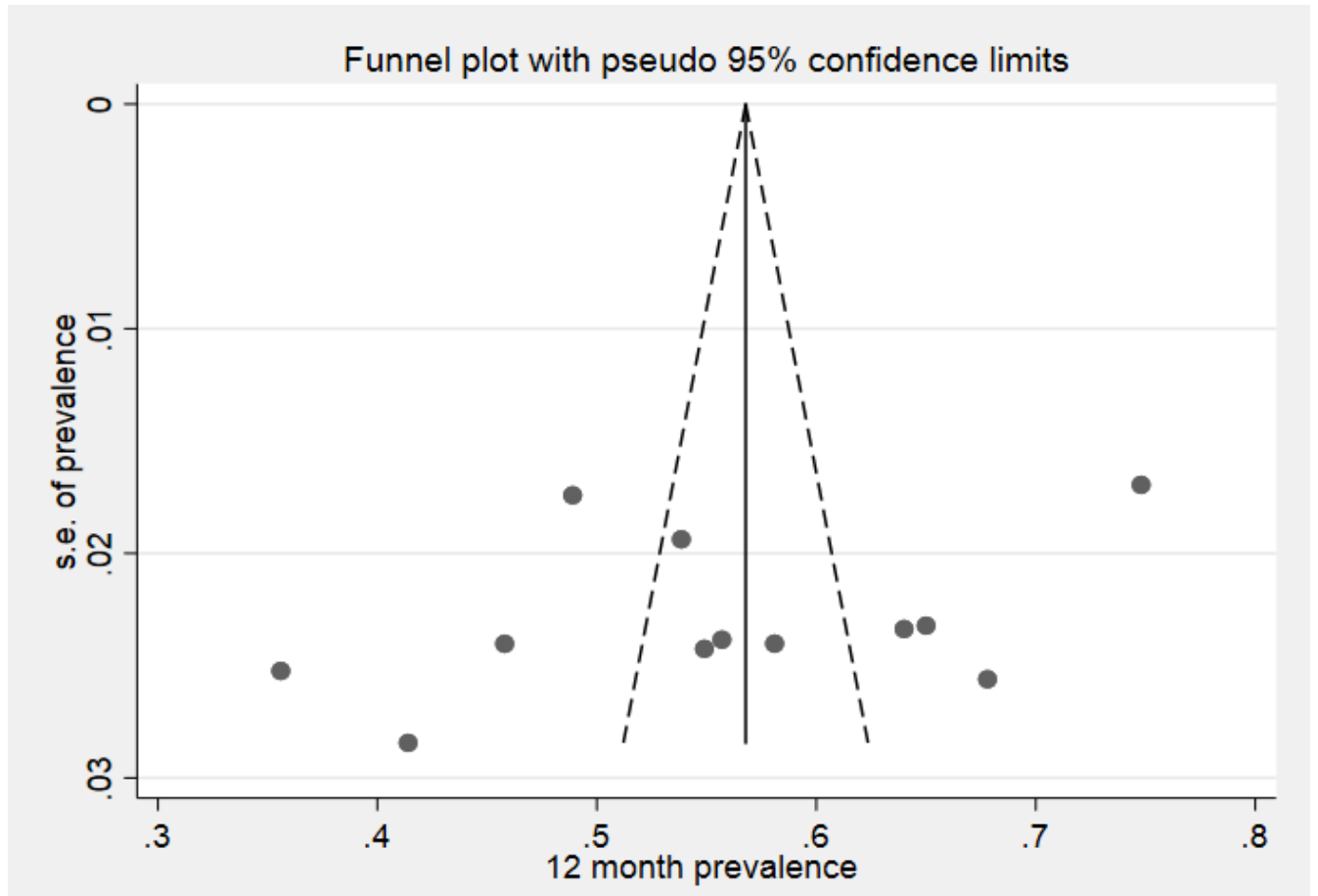

Figure 6. Meta funnel plot presentation of Prevalence of low back pain among working Ethiopian population $(\mathrm{S} . \mathrm{E}=$ Standard Error $)$ 
The review highlighted several challenges related to conducting and pooling relevant epidemiologic data. Some of these study weaknesses were: First, significant heterogeneity has been noted among included studies. Thus, the pooled prevalence estimate should be interpreted cautiously. Second, only the English language was used to retrieve studies. Third, many Ethiopian LBP studies are published in local journals or as a postgraduate thesis, and not all Ethiopian universities may have information technology systems that allow online access to their postgraduate thesis, which leads to difficulty in publishing, access and retrieving such publications. However, this study has several strengths that need to be mentioned: I) PRISMA guideline has been strictly followed, II) Large sample sizes have been included to estimate pooled prevalence, III) Publication bias assessment and sensitivity analysis have also been conducted to ensure the robustness of study, IV) Evaluation of possible sources of heterogeneity and trend analysis was also done.

\section{Conclusion}

The results showed a high prevalence of LBP among the working Ethiopian population, especially among the teachers. We believe that prevention strategies addressing the early onset of LBP among the working population would most likely be the answer to the burden of LBP on the future economy of Ethiopia.

\section{Competing interests:}

The authors declared no competing of interests.

\section{Funding:}

None.

\section{Authors' contributions}

AGA conceived the study, analyzed the data, and wrote the manuscript. AGA and GA conducted literature search, screening, data extraction, and quality assessment. SHM and SE supervised the work and reviewed the work critically. All authors reviewed and approved the final manuscript.

\section{Acknowledgements}

The authors would like to acknowledge International Campus management at Tehran University of Medical Sciences for their support.
1. Hoy, D., March, L., Brooks, P., Woolf, A., Blyth, F., Vos, T., et al. Measuring the global burden of low back pain. Best Pract Res Clin Rheumatol. 2010; 24(2):155-65.

2. Manchikanti, L. Epidemiology of low back pain. Pain Physician. 2000; 3(2):167-92.

3. Rubin, D.I. Epidemiology and risk factors for spine pain. Neurol Clin. 2007; 25(2):353-71.

4. Volinn, E. The epidemiology of low back pain in the rest of the world: a review of surveys in lowand middle-income countries. Spine. 1997; 22(15):1747-54.

5. Parent-Thirion, A., Vermeylen, G., van Houten, G., Lyly-Yrjänäinen, M., Biletta, I., Cabrita, J. Eurofound. Fifth European working conditions survey. Luxembourg: Publications Office of the European Union. 2012.

6. Thiese, M.S., Hegmann, K.T., Wood, E.M., Garg, A., Moore, J.S., Kapellusch, J., et al. Prevalence of low back pain by anatomic location and intensity in an occupational population. BMC Musculoskeletal Disorders. 2014; 15(1):283.

7. Thiese, M.S., Hegmann, K.T., Wood, E.M., Garg, A., Moore, J.S., Kapellusch, J.M., et al. Low-back pain ratings for lifetime, 1-month period, and point prevalences in a large occupational population. Hum Factors. 2014; 56(1):86-97.

8. Balague, F., Troussier, B., Salminen, J. Nonspecific low back pain in children and adolescents: risk factors. Eur Spine. 1999; 8(6):429-38.

9. Taimela, S., Kujala, U.M., Salminen, J.J., Viljanen, T. The prevalence of low back pain among children and adolescents: a nationwide, cohort-based questionnaire survey in Finland. Spine. 1997; 22(10):1132-6.

10. Waddell, G. Low back pain: a twentieth century health care enigma. Spine. 1996; 21(24):2820-5.

11. Katz, J.N. Lumbar disc disorders and low-back pain: socioeconomic factors and consequences. J Bone Joint Surg Am. 2006; 88(suppl_2):21-4.

12. Hoy, D., March, L., Brooks, P., Blyth, F., Woolf, A., Bain, C., et al. The global burden of low back pain: estimates from the Global Burden of Disease 2010 study. Ann Rheum Dis. 2014; 73(6):968-74.

13. Driscoll, T., Jacklyn, G., Orchard, J., Passmore, E., Vos, T., Freedman, G., et al. The global burden of occupationally related low back pain: Estimates from the Global Burden of Disease 2010 study. Ann Rheum Dis. 2014; 73(6):97581.

\section{References}


14. Fatoye, F., Gebrye, T., Odeyemi, I. Real-world incidence and prevalence of low back pain using routinely collected data. Rheumatol Int. 2019; 39(4):619-26.

15. Stroup, D.F., Berlin, J.A., Morton, S.C., Olkin, I., Williamson, G.D., Rennie, D., et al. Metaanalysis of observational studies in epidemiology: a proposal for reporting. JAMA. 2000; 283(15):2008-12.

16. Moher, D., Liberati, A., Tetzlaff, J., Altman, D.G., Group, P. Preferred reporting items for systematic reviews and meta-analyses: the PRISMA statement. PLoS Med. 2009; 6(7):e1000097.

17. Morris, L.D., Daniels, K.J., Ganguli B, Louw QA. An update on the prevalence of low back pain in Africa: a systematic review and metaanalyses. BMC Musculoskeletal Disorders. 2018;19(1):196.

18. Abebaw, T.A., Weldegebriel, M.K., Gebremichael, B., Abaerei, A.A. Prevalence and Associated Factors of Low Back Pain Among Teachers Working at Governmental Primary Schools in Addis Ababa, Ethiopia: A Cross Sectional Study. Biomed J Sci Tech Res. 2018; 10(1):7516-21.

19. Abebe, A.D., Gebrehiwot, E.M., Lema, S., Abebe, T.W. Prevalence of low back pain and associated risk factors among Adama Hospital Medical College Staff, Ethiopia. Eur J Prev Med. 2015; 3(6):188-92.

20. Belay, M,M, Worku, A., Gebrie, S.A., Wamisho, B. Epidemiology of low back pain among nurses working in public hospitals of Addis Ababa, Ethiopia. East Central Afr J Surg. 2016; 21(1):113-31.

21. Beyen, T.K., Mengestu, M.Y., Zele, Y.T. Low back pain and associated factors among teachers in Gondar Town, North Gondar, Amhara Region, Ethiopia. Occup Med Health Aff. 2013; 1(5):1-8.

22. Gebreyesus, T., Weldemariam, S., Fasika, S., Abebe, E., Kifle, M. Prevalence and Associated Factors of Low Back Pain among School Teachers in Mekelle City, Northern Ethiopia, 2016: A Cross Sectional Study. World J Phys Med Rehab 2019; 1:1006.

23. Kebede, A., Abebe, S.M., Woldie, H., Yenit, M.K. Low Back Pain and Associated Factors among Primary School Teachers in Mekele City, North Ethiopia: A Cross-Sectional Study. Occup Ther Int. 2019; 2019:3862946.

24. Lette, A., Ambelu, A., Getahun, T., Mekonen, S. A survey of work-related injuries among building construction workers in southwestern Ethiopia. Int J Indust Ergonomics. 2018; 68:5764.

25. Mekonnen, T.H. The magnitude and factors associated with work-related back and lower extremity musculoskeletal disorders among barbers in Gondar town, northwest Ethiopia, 2017: A cross-sectional study. Plos One. 2019; 14(7):e0220035.

26. Regassa, T., Lema, T., Garmomsa, G. Work Related Musculoskeletal Disorders and Associated Factors among Nurses Working in Jimma Zone Public Hospitals, South West Ethiopia. Occup Med Health Aff. 2018; 6(3):279.

27. Tefera Zele, Y., Ahmed, A.N., Wondie, Y., Yilma, T.M., Gebreegziabher, H.W, Weldegebreal, M.K., et al. Prevalence of low back pain and associated factors among young workers in traditional weaving of the informal sectors, Central and Southern Ethiopia. Vulnerable Children and Youth Studies. 2020; 15(1):48-59.

28. Wami, S.D., Abere, G., Dessie, A., Getachew, D. Work-related risk factors and the prevalence of low back pain among low wage workers: results from a cross-sectional study. BMC Public Health. 2019; 19(1):1072.

29. Wanamo, M.E., Abaya, S.W., Aschalew, A.B. Prevalence and risk factors for low back pain (LBP) among Taxi Drivers in Addis Ababa, Ethiopia: A community based cross-sectional study. Ethiop J Health Dev. 2017; 31(4):244-50.

30. Yosef, T., Belachew, A., Tefera, Y. Magnitude and Contributing Factors of Low Back Pain among Long Distance Truck Drivers at Modjo Dry Port, Ethiopia: A Cross-Sectional Study. J Environ Public Health. 2019; 2019:6793090.

31. Loney, P.L., Stratford, P.W. The prevalence of low back pain in adults: a methodological review of the literature. Phys Ther. 1999; 79(4):384-96.

32. Millennium WSGotBoMCatSotN, Organization WH. The burden of musculoskeletal conditions at the start of the new millennium: report of a WHO Scientific Group: World Health Organization; 2003.

33. Hoy, D., Bain, C., Williams, G., March, L., Brooks, P., Blyth, F., et al. A systematic review of the global prevalence of low back pain. Arthritis Rheum. 2012; 64(6):2028-37.

34. Hoy, D., Brooks, P., Blyth, F., Buchbinder, R. The epidemiology of low back pain. Best practice \& research Clin Rheum. 2010; 24(6):769-81. 
Arero, A.G. et al.

35. Yang, H., Haldeman, S., Lu, M.L., Baker, D. Low back pain prevalence and related workplace psychosocial risk factors: a study using data from the 2010 National Health Interview Survey. J Manipulative Physiol Ther. 2016; 39(7):45972.

36. March, L., Woolf, A.D. The global burden of musculoskeletal conditions-why is it important? Best Pract Res Clin Rheumatol. 2010; 24(6):721.

37. Woolf, A.D., Erwin, J., March, L. The need to address the burden of musculoskeletal conditions. Best Pract Res Clin Rheumatol. 2012; 26(2):183-224.

38. Froud, R., Patterson, S., Eldridge, S., Seale, C., Pincus, T., Rajendran, D., et al. A systematic review and meta-synthesis of the impact of low back pain on people's lives. BMC Musculoskeletal Disorders. 2014; 15(1):50.

39. Woolf, A.D., Brooks, P., Åkesson, K., Mody, G.M. Prevention of musculoskeletal conditions in the developing world. Best Pract Res Clin Rheumatol. 2008; 22(4):759-72. 